\title{
Effect of Educational Intervention Based on the Health Belief Model to Promote Metabolic Syndrome Preventive Behaviors in Premenopausal Women Over 40
}

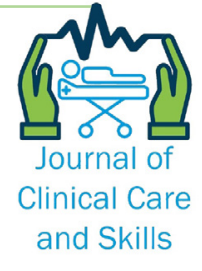

\section{ARTICLE INFO}

\section{Article Type}

Original Research

\section{Authors}

Karimzadeh Shirazi K. ${ }^{1} P h D$

Davoodi Sh. ${ }^{2}$ MSC,

Akbartabar Toori M.*3 $P h D$

How to cite this article
Karimzadeh Shirazi K, Davoodi Sh,
Akbartabar Toori M. Effect of Educa-
tional Intervention Based on the He-
alth Belief Model to Promote Metab-
olic Syndrome Preventive Behaviors
in Premenopausal Women Over 40.
Journal of Clinical Care and Skills.
2020;1(4):181-187.

${ }^{1 "}$ Public Health Department, School of Health" and "Social Determinants of Health Research Center", Yasuj University of Medical Sciences, Yasuj, Iran

${ }^{2}$ Student Research Committee, School of Health, Yasuj University of Medical Sciences, Yasuj, Iran

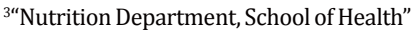
and "Social Determinants of Health Research Center", Yasuj University of Medical Sciences, Yasuj, Iran

\section{*Correspondence}

Address: Nutrition Department, School of Health, Yasuj University of Medical Sciences, Yasuj, Iran. Postal Code: 7591741417.

Phone: +98 (74) 33225519

Fax: +98 (74) 33226715

m_akbartabar@yahoo.co.uk

\section{Article History}

Received: December 27, 2019

Accepted: January 06, 2020

ePublished: October 01, 2020

\section{A B S T RAC T}

Aims Metabolic syndrome is a multi-faceted chronic disorder and it has been shown the spread of this disease has significant relationship with the age increase in women. The aim of this study was to investigate the effect of educational intervention based on health belief model constructs to promote metabolic syndrome preventive behaviors in premenopausal women over 40 .

Materials \& Methods This field clinical trial study was conducted on 130 premenopausal females over 40 from Gachsaran urban health centers in 2016. The two urban health centers in the city randomly were divided to intervention $(\mathrm{N}=65)$ and control $(\mathrm{N}=65)$ groups. The tools for collecting data were a three non-consecutives day 24-hour recall questionnaire for dietary intake, a check list for daily physical activity and a self-administered questionnaire containing demographic information, anthropometric measurements and questions related to the health belief model. After doing the pretest in both groups, only the intervention group was given instruction on preventive behaviors of metabolic syndrome disease. Data were analyzed by SPSS 22 software using paired t-test and independent t-test.

Findings In the intervention group the mean scores of perceived susceptibility, perceived severity, perceived benefits, perceived self-efficacy and knowledge significantly improved after the intervention $(\mathrm{p}<0.001)$. Consumption of fruits, vegetables and dairy products and physical activity increased and meats and energy intake decreased significantly in the intervention group after the intervention $(\mathrm{p}<0.05)$.

Conclusion Educational intervention based on the health belief model improves women's beliefs, knowledge and practice to prevent metabolic syndrome.

Keywords Educational Intervention; Health Belief Model; Metabolic Syndrome; Women; Premenopause

\section{I T A T I O N L I N K S}

[1] Executive summary of ... [2] Components of the "metabolic ... [3] Prevalence of the metabolic ... [4] Metabolic syndrome ... [5] The metabolic syndrome ... [6] The prevalence of metabolic ... [7] Prevalence of metabolic ... [8] The metabolic syndrome ... [9] The health belief model ... [10] Evaluation of efficacy ... [11] Structural role of perceived ... [12] Health belief model of breast cancer ... [13] Development and evaluation of ... [14] The use of the health belief model ... [15] Application of the health belief ... [16] National study of women's awareness ... [17] The effect of web-assisted ... [18] The implication of health beliefmodel... [19] Developmentand psychometrics of health ... [20] Development and psychometrics of health belief ... [21] Self-efficacy and perceived benefits ... [22] Effect of educational interventions on sexual ... [23] Dictionary of public health promotion and ... [24] The effect of health education based ... [25] The effect of education, based on health ... [26] The application of health belief model ... [27] Effects of a cognition-emotion focused ... [28] Factors associated with breast self-examination ... [29] A survey of the prevalence of self-medication ... [30] The role of exercise in the African ... [31] Using the Health Belief Model to examine ... [32] Human brucellosis in Kuwait: a prospective ... [33] Relationship between health belief ... [34] Health behavior and health education ... [35] The effect of empowerment model on ... [36] Utilizing the Health Promotion Model ... [37] The effectiveness of nutrition education ... [38] The effect of education based on Health ... [39] Application of the health belief model ... [40] Application of the Health Belief Model ... [41] Survey effect of education based on health ... [42] Results of an osteoporosis educational ... [43] Osteoporosis prevention education ... [44] A study in the efect of education through ... [45] Promoting health status of menopausal ... [46] Effects of bone density feedback and ... [47] Osteoporosis prevention project: A model ... [48] Osteoporosis knowledge among female ... 


\section{Introduction}

Metabolic syndrome includes a set of metabolic disorders such as abdominal obesity, dyslipidemia, impaired glucose homeostasis and hypertension. According to Adult Therapy Panel III (ATP), cardiovascular diseases are the first symptom of metabolic syndrome. This disease is a multi-faceted chronic disorder. Having a body mass index over 25 $\mathrm{Kg} / \mathrm{m}^{2}$ increases the probability of exposure to this disease. Clinical definition of this syndrome was put forth by World Health Organization (WHO), ATP III and US National Emergency Communication Plan (NCEP) in 2001.

Based on NCEP-ATP III criteria, metabolic syndrome is a collection of metabolic disorders such as the increase of triglyceride serum levels, decrease of High-density lipoprotein, abdominal obesity, high blood pressure and elevated fasting blood sugar [1]. According to NCEP definition, metabolic syndrome is the existence of three or more of the following factors: the increase of fasting plasma glucose level (higher than $110 \mathrm{mg} / \mathrm{dl}$ ) or taking medication for it, increase in the amount of triglycerides (greater than $200 \mathrm{mg} / \mathrm{dl}$ ), decrease in the level of HDL-cholesterol (in women less than $50 \mathrm{mg} / \mathrm{dl}$ and in men less than $40 \mathrm{mg} / \mathrm{dl})$, increase of hypertension $(130 / 85 \mathrm{mmHg}$ $\leq$ ) or taking medication for it, and abdominal obesity (waist circumference greater than $102 \mathrm{~cm}$ in men and greater than $88 \mathrm{~cm}$ in women) [1, 2].

According to the results of the third analysis NCEP in 2002 , the prevalence of this syndrome in US was in $23 \%$ of women and $24 \%$ of men. As a matter of fact, in US, one out of every four people is diagnosed with metabolic syndrome ${ }^{[3,4]}$. The third research by WHO in 2001 showed that the spread of metabolic syndrome disease had significant relationship with the age increase in women. The spread of the disease in women between 20 and 29 is $6 \%$, in women between 30-39 14\%, in women between 40-49 20\%, and in women over 50 the spread is $30 \%[1,2,5]$.

In a research carried out on 1143 males and females in Boyer Ahamd in 2009 the aggregate percentage of spread was $29.47 .14 .43 \%$ of the individuals in that study did not have any symptom; $27.47 \%$ had one; $28.38 \%$ had two; $19.07 \%$ had three; $8.39 \%$ had four, and 2.01 had five symptoms of this disease. The prevalence of this syndrome in the urban and rural population had no significant difference. The increase in age and body mass index increased the chance of exposure, and the highest prevalence of the disease was observed in the adults with 50-59 and 60-69 years. The prevalence of metabolic syndrome in the women was $39.1 \%$ and in the men $19.9 \%$. The reason that it was twice more prevalent in the women was that in comparison with the men they had more waist circumference and body mass index [6].

Changes in life style of people in society have caused the exponential increase of metabolic syndrome in different countries. These changes include environmental factors such as change of diet and physical exercise ${ }^{[4,7]}$. Various studies have addressed the relationship between menopause and metabolic syndrome. A study delivered in 2013 found that menopause affects all metabolic syndrome symptoms, and chance exposure increases during this period [8].

Health belief model is a very effective model in teaching health. This model shows the relation between health beliefs and health behaviors. It is based on the premise that preventive behavior is a result of personal beliefs. Metabolic syndrome is a chronic disease ${ }^{[1]}$, and health belief theory is a proper model for the prevention of chronic diseases especially when a researcher wants to teach those who are still safe from the disease ${ }^{[9]}$.

Therefore, the aim of this study was to investigate the effect of educational intervention based on health belief model constructs to promote metabolic syndrome preventive behaviors in premenopausal women over 40 .

\section{Materials and Methods}

This field clinical trial study was conducted in 2016 . The statistical population included 130 premenopausal females over 40 from Gachsaran urban health centers. The two urban health centers in the city randomly were divided to intervention and control groups. In a pilot study we found that almost $30 \%$ of the population consumed healthy diet, so that, assuming an alpha error of $5 \%$ with a power of $80 \%$ and a minimum difference of $25 \%$ in the intervention group compared to the control group after the intervention, and given more than $10 \%$ loss of the total sample during the intervention, 130 participants (65 in the intervention group and 65 in the control group) took part in the study. The inclusion criteria of the study were no history of illnesses associated with this disease (diabetes, cardiovascular disease, etc.), using no drug associated with the disease (e.g. fat-burning drugs, insulin, blood pressure drugs, etc.), and willingness to cooperate and to participate fully in the training sessions.

To collect data at baseline and two months after the intervention, a three non-consecutives day 24 hour recall questionnaire for dietary intake, a check list for daily physical activity and a self-administered questionnaire were used. For the self-administered questionnaire, first the questions were chosen and modified from valid questionnaires of other studies [10-14], and then its content and face validity were confirmed by an expert panel including experts in the fields of community nutrition and health promotion. To assess the reliability of the questionnaire, coefficient of Cronbach's alpha was used with a criteria more than 0.7 . The finalized questionnaire 
included 9 parts, demographic questions (6 questions) and anthropometric features (4 questions on height, weight, waist circumference and blood pressure).

The scale of model constructs included perceived "susceptibility" (5 questions), "severity" (5 questions), "benefits" (6 questions), "barriers" (6 questions), "self-efficacy" (6 questions), and cues to action (4 questions). In addition, the knowledge of the participants of the study was checked by 10 questions.

The intervention consisted of 4 training sessions that were conducted in one month (a 2-hour session each week) at Shahid Motahari Health Center in Gachsaran. The educational content related to the consumption of food groups was adjusted according to the National Nutrition Program for middle ages, and the content of physical activity education was also designed with the aim of doing at least 150 minutes of physical activity per week (5 days a week, 30 minutes daily). The educational materials were arranged in 4 booklets and were given to the participants at the end of each training session, which included: 1) Understanding metabolic syndrome, 2) Healthy lifestyle in middle age, 3) Nutrition principles for people 40-65 years old, and 4) Physical activity in middle age. The contents were transmitted to the learners using a lecture method and at the end of each session there was a possibility for two-way discussion and answering questions.

Data analysis was performed by SPSS 22 software using paired t-test and independent t-test.

\section{Findings}

$78.4 \%$ of those who participated in the study were housewives, $18.5 \%$ were employees, and $3.1 \%$ were retired. $57.7 \%$ of the participants had less than a diploma, $19.2 \%$ had diploma, and $23.1 \%$ had a university degree. More than $16 \%$ of the participants' husbands were workers, $38.5 \%$ were employees, $4.6 \%$ were employers, $29.2 \%$ worked in free market, and $7.7 \%$ were retired.

There was no significant difference between the control and intervention group at baseline with respect to the demographic and anthropometric information including age, age of husbands, number of siblings, height, weight, body mass index, waist circumference, diastolic and systolic blood pressure ( $>>0.05$; Table 1).

It was not observed any significant difference in terms of perceived susceptibility, perceived severity, perceived benefits, perceived barriers, perceived self-efficacy and knowledge before and after intervention in the control group ( $p>0.05)$. In the intervention group the mean scores of perceived susceptibility, perceived severity, perceived benefits, perceived self-efficacy and knowledge improved significantly after the intervention $(p<0.001)$. The
Karimzadeh Shirazi K. et al.

difference of cues to action construct was significant in both groups of control and intervention $(\mathrm{p}<0.001)$. The mean score of perceived barriers improved after the intervention, but it was not significant (Table 2).

There was no significant changes in food groups and energy intake, and amount of physical activity per week in the control group before and after the intervention $(p>0.05)$. The amounts of serving per day of fruits, vegetables and dairy products consumption increased and meats and energy intake decreased significantly in the intervention group after the intervention $(\mathrm{p}<0.05)$. The amount of physical activity per week also increased significantly after the intervention in this group $(\mathrm{p}<0.001$; Table $3)$.

Table 1) Comparing the mean of characteristics of the subjects in control and intervention groups (65 people per group) ${ }^{a}$

\begin{tabular}{lccc}
\multicolumn{1}{c}{ Parameters } & $\begin{array}{c}\text { Control } \\
\text { group }\end{array}$ & $\begin{array}{c}\text { Intervention } \\
\text { group }\end{array}$ & $\begin{array}{c}\text { p. } \\
\text { value }^{\mathbf{b}}\end{array}$ \\
\hline Age (years) & $42.82 \pm 2.47$ & $43.77 \pm 3.04$ & 0.12 \\
Age of husband (years) & $47.3 \pm 5.19$ & $48.71 \pm 6.24$ & 0.15 \\
Number of siblings & $2.91 \pm 1.45$ & $2.77 \pm 1.64$ & 0.7 \\
Height $(\mathrm{cm})$ & $157.02 \pm 7.14$ & $158.55 \pm 6.08$ & 0.1 \\
Weight $(\mathrm{Kg})$ & $71.92 \pm 11.85$ & $75.55 \pm 12.56$ & 0.98 \\
Body Mass Index $\left(\mathrm{Kg} / \mathrm{m}^{2}\right)$ & $29.24 \pm 4.92$ & $30.09 \pm 4.88$ & 0.95 \\
Waist circumference $(\mathrm{cm})$ & $96.34 \pm 11.47$ & $97.2 \pm 12.91$ & 0.13 \\
$\begin{array}{l}\text { Systolic blood pressure } \\
\text { (mm Hg) }\end{array}$ & $11.52 \pm 0.59$ & $11.29 \pm 0.72$ & 0.23 \\
$\begin{array}{l}\text { Diastolic blood pressure } \\
\text { (mm Hg) }\end{array}$ & $7.08 \pm 0.64$ & $6.69 \pm 0.63$ & 0.15 \\
\hline
\end{tabular}

${ }^{a}$ values are expressed as mean $\pm \mathrm{SD}$; ${ }^{b}$ Paired samples t-test

Table 2) Comparing the mean of health belief model constructs and knowledge values before and after the intervention in the both control and intervention groups

\begin{tabular}{|c|c|c|c|}
\hline Constructs & Before & After & p. value \\
\hline \multicolumn{4}{|c|}{ Perceived susceptibility } \\
\hline \multirow{2}{*}{$\begin{array}{l}\text { Control group } \\
\text { Intervention } \\
\text { group }\end{array}$} & $3.01 \pm 0.10$ & $3.01 \pm 0.11$ & 0.4 \\
\hline & $2.99 \pm 0.13$ & $3.96 \pm 0.20$ & 0.001 \\
\hline \multicolumn{4}{|c|}{ Perceived severity } \\
\hline \multirow{2}{*}{$\begin{array}{l}\text { Control group } \\
\text { Intervention } \\
\text { group }\end{array}$} & $3.00 \pm 0.01$ & $3.00 \pm 0.02$ & 0.4 \\
\hline & $2.98 \pm 0.13$ & $4.01 \pm 0.27$ & 0.001 \\
\hline \multicolumn{4}{|c|}{ Perceived benefits } \\
\hline \multirow{2}{*}{$\begin{array}{l}\text { Control group } \\
\text { Intervention } \\
\text { group }\end{array}$} & $3.62 \pm 0.38$ & $3.63 \pm 0.36$ & 0.6 \\
\hline & $3.63 \pm 0.46$ & 4.220 .33 & 0.001 \\
\hline \multicolumn{4}{|c|}{ Perceived barriers } \\
\hline \multirow{2}{*}{$\begin{array}{l}\text { Control group } \\
\text { Intervention } \\
\text { group }\end{array}$} & $2.65 \pm 0.44$ & $2.72 \pm 0.42$ & 0.4 \\
\hline & $2.60 \pm 0.48$ & $2.46 \pm 0.42$ & 0.06 \\
\hline \multicolumn{4}{|c|}{ Perceived self-efficacy } \\
\hline \multirow{2}{*}{$\begin{array}{l}\text { Control group } \\
\text { Intervention } \\
\text { group }\end{array}$} & $2.89 \pm 0.95$ & $3.00 \pm 0.81$ & 0.06 \\
\hline & $2.85 \pm 0.99$ & $4.00 \pm 0.66$ & 0.001 \\
\hline \multicolumn{4}{|l|}{ Cues to action } \\
\hline \multirow{2}{*}{$\begin{array}{l}\text { Control group } \\
\text { Intervention } \\
\text { group }\end{array}$} & $1.85 \pm 0.64$ & $2.42 \pm 0.35$ & 0.001 \\
\hline & $1.84 \pm 0.53$ & $2.53 \pm 0.41$ & 0.001 \\
\hline \multicolumn{4}{|l|}{ Knowledge } \\
\hline \multirow{2}{*}{$\begin{array}{l}\text { Control group } \\
\text { Intervention } \\
\text { group }\end{array}$} & $12.88 \pm 2.05$ & $13.03 \pm 1.95$ & 0.2 \\
\hline & 12.662 .13 & $17.11 \pm 1.59$ & 0.001 \\
\hline
\end{tabular}

a Paired samples t-test 
Effect of Educational Intervention Based on the Health Belief Model ..

Table3) Comparing the mean of food intake, energy and physical activity values before and after the intervention in the both control and intervention groups

\begin{tabular}{|c|c|c|c|}
\hline Variables & Before & After & p. value \\
\hline \multicolumn{4}{|c|}{ Fruits (serving/day) } \\
\hline \multirow{2}{*}{$\begin{array}{l}\text { Control group } \\
\text { Intervention } \\
\text { group }\end{array}$} & $2.19 \pm 1.10$ & $2.21 \pm 1.20$ & 0.8 \\
\hline & $2.24 \pm 1.10$ & $2.59 \pm 0.85$ & 0.05 \\
\hline \multicolumn{4}{|c|}{ Vegetables (serving/day) } \\
\hline \multirow{2}{*}{$\begin{array}{l}\text { Control group } \\
\text { Intervention } \\
\text { group }\end{array}$} & $2.67 \pm 0.90$ & $2.69 \pm 1.10$ & 0.8 \\
\hline & $3.87 \pm 1.60$ & $4.49 \pm 1.60$ & 0.05 \\
\hline \multicolumn{4}{|c|}{ Meats (serving/day) } \\
\hline \multirow{2}{*}{$\begin{array}{l}\text { Control group } \\
\text { Intervention } \\
\text { group }\end{array}$} & $10.18 \pm 3.40$ & $9.54 \pm 2.20$ & 0.1 \\
\hline & $10.64 \pm 3.20$ & $8.30 \pm 6.30$ & 0.01 \\
\hline \multicolumn{4}{|c|}{ Dairy products (serving/day) } \\
\hline \multirow{2}{*}{$\begin{array}{l}\text { Control group } \\
\text { Intervention } \\
\text { group }\end{array}$} & $0.49 \pm 0.20$ & $0.54 \pm 0.20$ & 0.1 \\
\hline & $0.49 \pm 0.40$ & $0.98 \pm 0.30$ & 0.01 \\
\hline \multicolumn{4}{|c|}{ Energy (Kcal/day) } \\
\hline \multirow{2}{*}{$\begin{array}{l}\text { Control group } \\
\text { Intervention } \\
\text { group }\end{array}$} & $2526.00 \pm 122.00$ & $2522.00 \pm 108.00$ & 0.1 \\
\hline & $2526.00 \pm 104.00$ & $2280.00 \pm 86.00$ & 0.001 \\
\hline \multicolumn{4}{|c|}{ Physical activity (min/week) } \\
\hline Control group & $76.00 \pm 129.00$ & $68.00 \pm 123.00$ & 0.2 \\
\hline $\begin{array}{l}\text { Intervention } \\
\text { group }\end{array}$ & $72.00 \pm 118.00$ & $196.00 \pm 144.00$ & 0.001 \\
\hline
\end{tabular}

\section{Discussion}

The findings of this research showed the impact of education on the increase of perceived susceptibility, perceived severity, perceived benefits, perceived self-efficacy and knowledge. It also had reductive significant impact on perceived barriers. In a study by Baghianimoghadam et al. ${ }^{[15]}$ on the impact of health belief model in the promotion of preventive factors in patients with heart failure, it was found that the mean scores for perceived susceptibility, perceived severity, perceived benefits, perceived self-efficacy and knowledge are significantly higher in the intervention group than in the control group. However, the mean score for perceived barriers was less in the intervention group in comparison to the control group.

Perceived susceptibility is a very important factor influencing one's preventive behaviors. Real and successful prevention depends on the real information about personal susceptibility and relevant threats. Besides, the understanding of a person regarding the rigor and severity of the disease and its outcomes is an important element of health belief model. It is more significant than primary prevention in adopting preventing behaviors [16]. The present study showed a significant difference regarding susceptibility between before and after the intervention in intervention group. This shows the positive impact of teaching on the elements of health belief model. It was the reason that the premenopausal women over 40 saw themselves exposed to metabolic syndrome disease. This finding is in agreement with the findings of another study whose goal was to investigate the impact of teaching on health beliefs, knowledge and prostate cancer early diagnosis behaviors. After giving the teaching, perceived susceptibility and screening regarding prostate cancer increased [17]. Studies by Rahmati Najjar Kalaei et al. [18], Vakili et al. [19] and Fallahi [20] also showed that teaching could increase perceive susceptibility to disease.

In the present study, there was significant difference between before and after the intervention in terms of perceived severities in the intervention group. This shows that the participants believed they were exposed to metabolic syndrome and deemed it dangerous. A reason for the appropriateness of using health belief model for a chronic disease such as metabolic syndrome is its unpleasant outcomes. Knowing the consequences of the illness, people tend to adopt preventive measures. The findings of various studies done in Iran on perceived severity are in agreement with the finding of this research that the perceived severity increased after the intervention [21,22]. This finding is also in line with another study with the goal of investigating the impact of teaching by health belief framework on the knowledge, health beliefs and behaviors of diabetes patients [23]. People's perception and evaluation of threat is the axis of using health belief model, thus perceived severity as the element of weak behavior should increase [24].

We observed the increase of perceived benefits after the intervention in the intervention group. The most important perceived benefit regarding the preventing behaviors of metabolic syndrome was having a healthy body in case of adopting these behaviors. Karimi et al. [25] showed that there is a significant relationship between perceived benefits and AIDS preventive measures. This is also in line with the findings of Fallahi ${ }^{20]}$ and Mirheydari et al. [22]. The increase of perceived benefits is in agreement with the findings of Ghofranipour's study in Shahrekord [26], the study of Park et al. [27] in Korean, and Fung's study ${ }^{[28]}$ on Hong Kong women. According to the viewpoint of researchers, one's perception of benefits paves the way for taking preventing behaviors.

The women's perception of barriers to preventive behaviors in the both groups was similar before the intervention, and no significant difference was observed after the intervention in two groups. The most perceived barriers to metabolic syndrome preventive behaviors from the viewpoint of the women were respectively cost, being unpleasant, inconvenience and disrupting everyday life, family disapproval, tediousness and being time consuming. In Shamsi and Bayati study [29], the decrease of barriers led to less self-treatment by women. Koch [30] found that after overcoming the barriers, diabetic patients tended to jog more often. Ghofranipour found that after the intervention, the intervention group had fewer barriers to adopting behaviors preventing brucellosis [26]. 
In this study, there was a significant difference in the perceived self-efficacy before and after the intervention in intervention group. Other studies have shown that there is a significant relation between perceived self-efficacy and preventive measures [31,32], hence it should be observed in designing instructional programs for women. As a result, self-efficacy could have significant relationship with the emergence of preventive behaviors. As a matter of fact, it is the prologue to a behavior and should be taken into consideration since it is not only enough for one to know what to do why to do it, but he/she should also feel potent in doing that specific behavior [33]. Investigations have shown that self-efficacy has a significant impact on health behaviors, and high self-efficacy could increase ability, capability, merit and competence [34]. Corresponding to the findings of this research, Heidari et al. [35] found that after teaching diabetic adolescents, their self-efficacy increased. The findings are in agreement with the study of Mehri et al. [36], which focused on dental health behaviors of university students.

The most important clues to action before the intervention were respectively recommendation from friends and acquaintances, medical advice, reading books, and media. After the intervention, the most important clues were respectively doctor's advice, recommendations of friends and acquaintances, the mass media, and reading books. The investigations showed the existence of significant differences in the control and intervention groups before and after the intervention. This shows teaching has no impact on clue to action. Contrary to this research, several studies including Sharifirad et al. [37], Mardani Hamoole and Shahraki Vahed [38], Zamani Alavijeh et al. [39], Hazavehei et al. [40], Babamohammadi et al. [41], Nieto-Vázquez et al. [42], Tussing et al. [43] showed significant difference after intervention. It seems that in some studies, more limited number of elements is emphasized on. In fact, health belief model defines one's behaviour in terms of three factors: perceived threat that is the combination of perceived susceptibility and severity, perceived benefits and barriers, and clue to action. One, two or all of these three factors play the role of behavior [44]. Therefore, sometimes emphasis on one or more of these factors could change the desired behavior. However, promoting all of the factors may have a more appropriate impact. In this study, clue to action was increase in the both groups. The reason for this increase in the control group could be their personal attempts to become more familiar with this disease.

In this study, knowledge score in the control group was increased after the intervention which might be because of the participants' own attempts and researching. In the intervention group, knowledge was increase, which shows the high impact of teaching on improving knowledge. Significant

Journal of Clinical Care and Skills
Karimzadeh Shirazi K. et al.

promotion of knowledge in the intervention group is also observed in other studies (studies using or not using a model) such as the study of Golyan Tehrani et al. [45] in the promotion of menopausal women health via teaching self-care; the research by Winzenberg et al. ${ }^{46]}$ on the effects of bone density feedback and education on osteoporosis knowledge in premenopausal women; the study of Brecher et al. [47] on osteoporosis prevention education and the investigation of Sharifirad et al. ${ }^{[37]}$ on the efficiency of nutrition education on diabetic patients based on health belief model. There are other studies on prevention of osteoporosis using health belief model like those of Abushaikha et al. [48] and Nieto-Váquez et al. [42], which indicate a significant increase of knowledge. Apart from increasing the knowledge of the participants about metabolic syndrome, the educational intervention model significantly improved healthy lifestyle behaviors by increasing consumption of vegetables, fruits, dairy products, and decreasing consumption of meats and energy intake. It has also increased weekly physical activity. These positive changes in lifestyle can reduce the risk of metabolic syndrome in this group.

In conclusion, due to the effective role of this model in increasing the knowledge and practice of the participants and improving healthy lifestyle behaviors such as diet and physical activity, and the beliefs of premenopausal women over 40, it is suggested that it be included in the education program for this group. Besides the comparison of the efficiency of this model with other education models in educating premenopausal women over 40 , it can increase the efficiency of education in this age group. Therefore, this model increases women's perception of danger factors and benefits, and thus helps to overcome of barriers and improving premenopausal women performance to prevent metabolic syndrome.

There were some limitations in this study. All subjects of the study were from urban areas and also there were only two urban health centers in the city which were randomly divided to intervention and control groups. There were not similar studies in Iran to compare our findings with them. The other limitations of the study might be the short duration of the intervention, the low number of training sessions for education, and short time to assess the intervention effects that may limit the longitudinal aspect of this study. Therefore, we suggest further research to assess the effects of longer education period with diverse participants, and longer intervention durations on the outcome.

\section{Conclusion}

Educational intervention based on the health belief model improves women's beliefs, knowledge and practice to prevent metabolic syndrome.

Acknowledgements: This article was extracted from MSc 
thesis in health promotion. The authors appreciate the research deputy of Yasuj University of Medical Sciences for sponsoring the study. We would like to thank all the participants who sincerely cooperated in this study and also health professionals of Gachsaran health centers who support the study.

Ethical Permission: The study was approved by the Yasuj University of Medical Sciences Ethics Committee with Ethic Code No. IR. YUMS.REC.1394.84 and has been registered at the Iranian Clinical Trial Web site with No. IRCT2016011924987N1. The confidentiality of the collected information, informed consent to participate and freely withdrawal at each stage of the study were emphasized.

Conflict of Interests: The authors declare that there is no conflict of current or potential interest in the study.

Authors' Contribution: Karimzadeh Shirazi K. (First author), Introduction author/ Methodologist/ Original researcher/ Statistical analyst/ Discussion author (35\%); Davoodi S. (Second author), Original researcher/ Discussion author (30\%); Akbartabar Toori M. (Third author), Introduction author/ Methodologist/ Original researcher/ Statistical analyst/ Discussion author (35\%)

Funding: The present research was funded by Yasuj University of Medical sciences, Iran.

\section{References}

1- Expert Panel on Detection, Evaluation, and Treatment of High Blood Cholesterol in Adults. Executive summary of the third report of the national cholesterol education program (NCEP) expert panel on detection, evaluation, and treatment of high blood cholesterol in adults (adult treatment panel III). JAMA. 2001;285(19):2486-97.

2- Hanson RL, Imperatore G, Bennett PH, Knowler WC. Components of the "metabolic syndrome" and incidence of type 2 diabetes. Diabetes. 2002;51(10):3120-7.

3- Ford ES, Giles WH, Dietz WH. Prevalence of the metabolic syndrome among US adults: findings from the third national health and nutrition examination survey. JAMA. 2002;287(3):356-9.

4- Halpern A, Mancini MC, Magalhães ME, Fisberg M, Radominski R, Bertolami MC, et al. Metabolic syndrome, dyslipidemia, hypertension and type 2 diabetes in youth: from diagnosis to treatment. Diabetol Metab Syndr. 2010;2(1):55.

5- Cameron AJ, Shaw JE, Zimmet PZ. The metabolic syndrome: prevalence in worldwide populations. Endocrinol Metab Clin North Am. 2004;33(2):351-75.

6- Akbari F. The prevalence of metabolic syndrome and its influencing factors in the city Boyer Ahmad [Dissertation], Yasuj: University of Medical Sciences and Health Services Kohgiluyeh Boyer Ahmad; 2011. [Persian]

7- Azizi F, Salehi P, Etemadi A, Zahedi-Asl S. Prevalence of metabolic syndrome in an urban population: Tehran Lipid and Glucose Study. Diabetes Res Clin Pract. 2003;61(1):2937.

8- Liang H, Chen X, Chen Q, Wang Y, Wu X, Li Y, et al. The metabolic syndrome among postmenopausal women in rural canton: prevalence, associated factors, and the optimal obesity and atherogenic indices. PLoS ONE. 2013;8(9):e74121.

9- Becker MH, Maiman LA, Kirscht JP, Haefner DP, Drachman RH. The health belief model and prediction of dietary compliance: a field experiment. J Health Soc Behav. 1977;18(4):348-66.
10- Mohebi S, Azadbakhat L, Feizi A, Sharifirad G, Hozoori M, Sherbafchi M. Evaluation of efficacy associated with macronutrient intake in women with metabolic syndrome: a study of path analysis. Iran J Diabetes Metab. 2011;12(1):56-67. [Persian]

11- Mohebi S, Azadbakhat L, Feizi A, Hozoori M, Sharifirad G. Structural role of perceived benefits and barriers in receiving macronutrients in women with metabolic syndrome; a path analysis study. J Isfahan Med Sch. 2013;31(248):1226-38. [Persian]

12- Frankenfield KM. Health belief model of breast cancer screening for female college students [Dissertation]. Ypsilanti, Michigan: Eastern Michigan University; 2009.

13- Dedeli O, Fadiloglu C. Development and evaluation of the health belief model scale in obesity. TAF Prev Med Bull. 2011;10(5):533-42.

14- Coe AB, Gatewood SB, Moczygemba LR, Goode JV, Beckner J0. The use of the health belief model to assess predictors of intent to receive the novel (2009) H1N1 influenza vaccine. Innov Pharm. 2012;3(2):1-11.

15- Baghianimoghadam MH, Shogafard G, Sanati HR, Baghianimoghadam B, Mazloomy SS, Askarshahi M. Application of the health belief model in promotion of selfcare in heart failure patients. Acta Med Iran. 2013;51(1):52-8.

16- Mosca L, Mochari H, Christian A, Berra K, Taubert K, Mills T, et al. National study of women's awareness, preventive action, and barriers to cardiovascular health. Circulation. 2006;113(4):525-34.

17- Çapik C, Gozum S. The effect of web-assisted education and reminders on health belief, level of knowledge and early diagnosis behaviors regarding prostate cancer screening. Eur J Oncol Nurs. 2012;16(1):71-7.

18- Rahmati Najjar Kalaei F, Niknami S, Amin Shokravi F, Ahmadi F, Jafari M, Rahnama P. The implication of health belief model in planning educational programmes for preventing HIV/AIDS among university students. Payesh. 2009;8(4):349-59. [Persian]

19- Vakili MM, Heidarnia A, Niknami S, Mousavinasab N. Development and psychometrics of health belief model instrument about HIV/AIDS. Zahedan J Res Med Sci. 2012;14(9):64-71.

20- Fallahi H. Effect of educational intervention on reproductive health behavior change among HIV-AIDS on the health belief model [Dissertation]. Tehran: Shahid Beheshti University; 2012. [Persian]

21- Karimi M, Niknami S. Self-efficacy and perceived benefits/barriers on the AIDS preventive behaviors. J Behboud. 2011;15(5):384-92. [Persian]

22- Mirheydari M, Tavafian SS, Montazeri A, Fallahi H. Effect of educational interventions on sexual high risk behavior between drug addicts ex-users based on the Health Belief Model. J Sch Public Health Inst Public Health Res. 2014;12(2):93-104. [Persian]

23- Modeste NN, Tamayose TS. Dictionary of public health promotion and education: terms and concepts. $2^{\text {nd }}$ Edition. San Fravcisco: John Wiley \& Sons; 2004.

24- Sharifirad G, Hazavei MM, Hasanzadeh A, Daneshamouz A. The effect of health education based on health belief model on preventive actions of smoking in grade one, middle school students. J Arak Uni Med Sci. 2007;10(1):7986. [Persian]

25- Karimi M, Hasani M, Khorram R, Ghaffari M, Niknami S. The effect of education, based on health belief model on breast self-examination in health liaisons of Zarandieh city. Zahedan J Res Med Sci. 2009;10(4):283-91. [Persian] 


\section{7}

26- Ghofranipour F. The application of health belief model on prevention brucellosis in the Shahrekord [Dissertation]. Tehran: Tarbiat Modares University; 1998. [Persian]

27- Park S, Chang S, Chung C. Effects of a cognition-emotion focused program to increase public participation in Papanicolaou smear screening. Public Health Nurs. 2005;22(4):289-98.

28- Fung SY. Factors associated with breast selfexamination behaviour among Chinese women in Hong Kong. Patient Educ Couns. 1998;33(3):233-43.

29- Shamsi M, Bayati A. A survey of the prevalence of selfmedication and the factors affecting it in pregnant mothers referring to health centers in Arak city, 2009. Jahrom Med J. 2010;7(4):34-42. [Persian]

30- Koch J. The role of exercise in the African- American woman with type 2 diabetes mellitus: application of the health belief model. J Am Acad Nurse Pract. 2002;14(3):126-9.

31- Burak LJ, Meyer M. Using the Health Belief Model to examine and predict college women's cervical cancer screening beliefs and behavior. Health Care Women Int. 1997;18(3):251-62.

32- Lulu AR, Araj GF, Khateeb MI, Mustafa MY, Yusuf AR, Fenech FF. Human brucellosis in Kuwait: a prospective study of 400 cases. Q J Med. 1988;66(249):39-54.

33- Ramezankhani A, Mazaheri M, Dehdari T, Movahedi M. Relationship between health belief model constructs and DMFT among five-grade boy students in the primary school in Dezfool. Jundishopur Sci Med J. 2011;10(2):221-8. [Persian]

34- Glanz K, Rimer BK, Viswanath K, editors. Health behavior and health education: theory, research, and practice. $4^{\text {th }}$ Edition. San Francisco: Jossey-Bass; 2008.

35- Heidari M, Alhani F, Kazemnejad A, Moezzi F. The effect of empowerment model on quality of life of Diabetic adolescents. Iran J Pediatr. 2007;17(Suppl 1):87-94. [Persian]

36- Mehri A, Morowati Sharifabad MA. Utilizing the Health Promotion Model to predict oral health behaviors in the students of Islamic Azad University of Sabzevar. J Dent Med. 2009;22(1):81-7. [Persian]

37- Sharifirad GR, Entezari MH, Kamran A, Azadbakht L. The effectiveness of nutrition education for patients with type 2 diabetes: the Health Belief Model. Iran J Diabetes Metab. 2008;7(4):379-86. [Persian]
Karimzadeh Shirazi K. et al.

38- Mardani Hamoole M, Shahraki Vahed A. The effect of education based on Health Belief Model on adherence to the diabetic diet. Iran J Diabetes Metab. 2010;9(3):268-75. [Persian]

39- Zamani Alavijeh F, Faghihzadeh S, Sadeghi F. Application of the health belief model for unhealthy eating prevention among primary school children in Arak/Iran (20042005). J Kermanshah Univ Med Sci. 2008;11(4):35267. [Persian]

40- Hazavehei SM, Taghdisi MH, Saidi M. Application of the Health Belief Model for Osteoporosis prevention among Middle school Girl students, Garmsar, Iran. Educ Health. 2007;20(1):23.

41- Babamohammadi H, Asgari Majdabadi H, Kahoei M. Survey effect of education based on health promotion model on health volunteer's empowerment of health service in preventing of osteoporosis. J Daneshvar Med. 2005;13(59):11-18. [Persian]

42- Nieto-Vázquez M, Tejeda MJ, Colin J, Matos A. Results of an osteoporosis educational intervention randomized trial in a sample of Puerto-Rican women. J Cult Divers. 2009;16(4):171-7.

43- Tussing L, Chapman-Novakofski K. Osteoporosis prevention education: behavior theories and calcium intake. J Am Diet Assoc. 2005;105(1):92-7.

44- Khazaeipool M, Ebadifard Azar F, Solhi M, Asadi Lari M, Abdi N. A study in the efect of education through health belief model on the perceptions of girl students in primary school about breakfast and snack in Noshahr-2007. Tolooe Behdasht. 2008;7(1 and 2):51-65. [Persian]

45- GolyanTehrani S, Ghobadzade M, Arasto M. Promoting health status of menopausal women by educating self care strategies. Hayat J. 2007;13(3):67-75. [Persian]

46- Winzenberg TM, Oldenburg B, Frendin S, De Wit L, Jones G. Effects of bone density feedback and grop education on osteoporosis knowledge and osteoporosis self-efficacy in premenopausal women: a randomized controlled trial. J Clin Densitom. 2005;8(1):95-103.

47- Brecher LS, Pomerantz SC, Snyder BA, Janora DM, Klotzbach-Shimomura KM, Cavalieri TA. Osteoporosis prevention project: A model multidisciplinary educational intervention. J Am Osteopath Assoc. 2002;102(6):327-35.

48- Abushaikha L, Omran S, Barrouq L. Osteoporosis knowledge among female school students in Jordan. East Mediterr Health J. 2009;15(4):906-11. 